\title{
ANATOMICAL AND FUNCTIONAL OUTCOME OF COMMINUTED INTRA-ARTICULAR DISTAL RADIAL FRACTURES TREATED WITH VOLAR BUTTRESS PLATING AND ANTI-IMPACTION KIRSCHNER WIRE THROUGH THE RADIAL STYLOID
}

\author{
K. Kumaran Chettiar1, Mohammed Rafi², Lakshmi Rajamma ${ }^{3}$
}

${ }^{1}$ Additional Professor, Department of Orthopaedics, Government Medical College, Manjeri Malappuram Hospital, Kerala, India.

${ }^{2}$ Senior Resident, Department of Orthopaedics, Government Medical College, Manjeri Malappuram Hospital, Kerala, India.

3 Senior Resident, Department of Orthopaedics, Government Medical College, Manjeri Malappuram Hospital, Kerala, India.

\section{ABSTRACT}

\section{BACKGROUND}

Comminuted Colles' fracture is common after accident and fall from height. Residual deformity after treatment adversely affect wrist motion and hand function.(1) Collapse on metaphysis and radial styloid with secondary osteoarthritis of wrist is common with comminution and displacement.(2) An anti-impaction K-wire is passed through radial styloid to medial cortex to prevent collapse along with ORIF with buttress plate.(3)

\section{MATERIALS AND METHODS}

This cohort study was to evaluate the functional and anatomical outcome of ORIF with plate and K-wire of Type-C distal radial fracture of 30 patients with intra-articular comminution AO type C1, C2 and C3 fracture between the aged 30 and 50 years. Polytrauma patients are excluded. All patients underwent ORIF through volar approach with buttress plate and anti-impaction care through radial styloid. After 4 weeks, K-wire was removed, and mobilisation started. Repeat x-ray was taken at $6^{\text {th }}$, $9^{\text {th }}$ and $12^{\text {th }}$ month. Evaluation is done with demerit point system and Gartland and Werley's with Sarmiento modification.

\section{RESULTS}

We have got $73.3 \%$ excellent and $20 \%$ good result. In $66.7 \%$, dorsal tilt is restored to anatomical palmar tilt and radial shortening is restored in $70.3 \%$ patient. Radiological evaluation was restored in 76\% patients at final follow-up. On subject evaluation, $73.3 \%$ had excellent result and 1 poor result due to early spontaneous removal of K-wire loosening.

\section{CONCLUSION}

We have obtained 93\% anatomical and 93\% functional results. Our observation suggested stabilising distal radius fracture with volar plate and anti-impaction K-wire through radial styloid. It is an effective method to prevent collapse and maintaining reduction till union, even when the fracture is comminuted and helps to prevent secondary osteoarthritis of the wrist.

\section{KEYWORDS}

Comminuted Distal Radial Fracture, Anti-Impaction K-Wire.

HOW TO CITE THIS ARTICLE: Chettiar KK, Rafi M, Rajamma L. Anatomical and functional outcome of comminuted intra-articular distal radial fractures treated with volar buttress plating and anti-impaction Kirschner wire through the radial styloid. J. Evolution Med. Dent. Sci. 2018;7(16):2038-2043, DOI: 10.14260/jemds/2018/458

\section{BACKGROUND}

Approximately, $1 / 6^{\text {th }}$ of all fractures coming into casualty is fracture distal radius ${ }^{(4)}$ and are common fractures of the upper extremity, encountered in practice and constitutes $17 \%$ of all fractures.(5) Since first described by Abraham Colles in 1814 most physicians have considered distal radial fractures to be a homogenous group of injuries that can be successful nonoperatively and results in favourable outcomes. A Colles' fracture as such defined as the complete fracture within the distal $2 \mathrm{~cm}$ metaphysis of the radius with dorsal displacement of the distal fragment in post-menopausal women which is different from other intra-articular fractures.(6)

'Financial or Other Competing Interest': None.

Submission 13-01-2018, Peer Review 01-04-2018,

Acceptance 09-04-2018, Published 16-04-2018.

Corresponding Author:

Dr. K. Kumaran Chettiar,

Panchami, CC-8/776,

Pipeline Road, Malaparamba,

Kozhikode-673009,

Kerala, India.

E-mail:drchettiar@rediffmail.com

DOI: $10.14260 /$ jemds $/ 2018 / 458$
Collapse of the metaphysis, radial styloid shortening and late-onset osteoarthritis of radiocarpal joint due to intraarticular involvement and radial styloid shortening, as more specifically stated in the reports of Leung and co-authors in their review of 100 cases $93 \%$ with intra-articular involvement, $73.6 \%$ moderate-to-severe comminution and 81.9\% marked or severe displacement.(7)

Most common complication associated with distal radial fracture is malunion(1) and most important way to avoid malunion is to prevent dorsal metaphyseal collapse.(8) Dorsal plating is the best method to prevent distal metaphyseal collapse. We propose another way to prevent metaphyseal collapse by an anti-impaction K-wire passing from distal radial styloid proximally to the medial cortex proximal to the fracture.

To find the anatomical and functional results of antiimpaction Kirschner wire fixation along with volar buttress plating in young adults with intra-articular comminution treated in the Department of Orthopaedics, Medical College Hospital, Kozhikode. The anatomical evaluation by Sarmiento's modification of Lindstrom's criteria and clinical and functional evaluation by Demerit point system of Gartland and Werley with Sarmiento et al modifications. 
MATERIALS AND METHODS

Study Design

Cohort study.

\section{Inclusion Criteria}

Intra-articular comminuted distal radial fractures (AO Type C1, C2 and C3 fractures).

\section{Exclusion Criteria}

- Patients with ipsilateral forearm or arm injuries.

- Patients with associated carpal bone injuries.

- Patients with pathological fractures.

- Patients with open fractures.

\section{Methods}

After receiving Institutional Research Committee approval and written informed consent, the patients are taken up for surgery within the first week once the local oedema and other inflammatory signs subsided. Immediately after admission, the patients are given short arm slab and elevation to reduce oedema. Pre-operative antibiotics (1 gram Reflin) given 1 hour prior to surgery and continued for next 48 hours, a total of six doses will be given. All the surgical procedures are done under axillary block.

Surgical approach- volar Henry's approach- exposing distal articular surface of the radius. Fracture fragments are reduced and fixed with volar buttress plate and anti-impaction $\mathrm{K}$-wire is passed through radial styloid to the medial cortex of the distal radius proximal to the fracture site and its tip will be kept outside. The wound closed in layers and short arm slab given. On tenth postop day, wound inspection and suture removal will be done. Immobilisation will be continued for 3 weeks and anti-impaction K-wire removed at three weeks.
Patients will be followed on third, sixth and twelfth month. Results are assessed using Sarmiento's modification of Lindstrom criteria for anatomical evaluation and demerit point system of Gartland and Werley's with Sarmiento's modification and comparing our results among pre-operative and post-operative cases.

\section{Radiological Assessment}

Radiological assessment was done in terms of residual dorsal angulation, radial shortening and loss of radial inclination and the results were graded according to the Sarmiento's modification of Lindstrom criteria.(9) These parameters were assessed during the follow-up of the patients to assess the quality of reduction and the ability of the technique to maintain the reduction.

Anatomical Evaluation- Sarmiento's Modification of Lindstrom Criteria

\begin{tabular}{|c|c|c|c|c|}
\hline Deformity & $\begin{array}{c}\text { Residual } \\
\text { Dorsal } \\
\text { Tilt }\end{array}$ & $\begin{array}{c}\text { Radial } \\
\text { Shortening }\end{array}$ & $\begin{array}{c}\text { Loss of } \\
\text { Radial } \\
\text { Inclination }\end{array}$ \\
\hline Excellent & $\begin{array}{c}\text { No or } \\
\text { Insignificant }\end{array}$ & $0^{\circ}$ & $<3 \mathrm{~mm}$ & $<5^{\circ}$ \\
\hline Good & Slight & $1^{\circ}$ to $10^{\circ}$ & 3 to $6 \mathrm{~mm}$ & $5^{\circ}$ to $9^{\circ}$ \\
\hline Fair & Moderate & $11^{\circ}$ to $14^{\circ}$ & 7 to $11 \mathrm{~mm}$ & $10^{\circ}$ to $14^{\circ}$ \\
\hline Poor & Severe & At least $15^{\circ}$ & $\begin{array}{c}\text { At least } \\
12 \mathrm{~mm}\end{array}$ & $>14^{\circ}$ \\
\hline
\end{tabular}

\section{Clinical and Functional Assessment}

Functional evaluation of the patients was done at the last follow-up according to the demerit point system of Gartland and Werley with Sarmiento et al's modification.

\section{Demerit Point System used to Evaluate End Results of Healed Colles' Fracture}

\begin{tabular}{|c|c|}
\hline Result & Points \\
\hline \multicolumn{2}{|l|}{ RESIDUAL DEFORMITY } \\
\hline Prominent ulnar styloid & 1 \\
\hline Residual dorsal tilt & 2 \\
\hline Radial deviation of the hand & 2 to 3 \\
\hline \multicolumn{2}{|l|}{ SUBJECTIVE EVALUATION } \\
\hline Excellent: No pain, disability or limitation of motion & 0 \\
\hline Good: Occasional pain, slight limitation of motion, no disability & 2 \\
\hline $\begin{array}{l}\text { Fair: Occasional pain, some limitation of motion, feeling of weakness in wrist, no particular disability, } \\
\text { activities slightly restricted }\end{array}$ & 4 \\
\hline Poor: Pain, limitation of motion, disability, activities more or less markedly restricted & 6 \\
\hline \multicolumn{2}{|l|}{ OBJECTIVE EVALUATION } \\
\hline \multicolumn{2}{|l|}{ Loss of dorsiflexion } \\
\hline Loss of ulnar deviation & 5 \\
\hline Loss of supination & 3 \\
\hline Loss of palmar flexion & 2 \\
\hline Loss of radial deviation & 1 \\
\hline Loss of circumduction & 1 \\
\hline Loss of pronation & 1 \\
\hline Pain in DRUJ & 2 \\
\hline \multirow[t]{2}{*}{ Grip strength- $60 \%$ or less of opposite side } & 1 \\
\hline & 1 \\
\hline \multicolumn{2}{|l|}{ COMPLICATIONS } \\
\hline \multicolumn{2}{|l|}{ Arthritic change } \\
\hline \multicolumn{2}{|l|}{ Minimum } \\
\hline Minimum with pain & 1 \\
\hline
\end{tabular}




\begin{tabular}{|l|c|}
\hline Moderate & 3 \\
Moderate with pain & 2 \\
Severe & 4 \\
Severe with pain & 3 \\
Nerve complications (median) & 5 \\
Poor finger function due to cast & 1 to 3 \\
& 1 to 2 \\
END RESULT POINT RANGES & 0 to 2 \\
Excellent & 3 to 8 \\
Good & 9 to 20 \\
Fair & 21 and above \\
Poor & \\
\hline
\end{tabular}

The objective evaluation is based on the following ranges of motion as being the minimum for normal function: dorsiflexion 45 degrees; palmar flexion 30 degrees; radial deviation 15 degrees; ulnar deviation 15 degrees; pronation 50 degrees; supination 50 degrees.

Statistical Methods- Qualitative variables were summarised as frequency and percentages. Scores were summarised as mean and standard deviation. Wilcoxon Signed Rank Test was used to compare the statistical significance of pre-intervention to post-intervention change in scores. A ' $p$ ' value of $<0.05$ was considered as statistically significant.

\section{RESULTS}

The study comprised a total of thirty patients of fractures of the distal radius presenting to Government Medical College Hospital, Calicut during July 2010 to July 2012.

\begin{tabular}{|c|c|c|}
\hline & Frequency & Percent \\
\hline Valid fall & 28 & 93.3 \\
RTA & 2 & 6.7 \\
Total & $\mathbf{3 0}$ & $\mathbf{1 0 0}$ \\
\hline \multicolumn{3}{|c|}{ Mode of Injury } \\
\hline
\end{tabular}

The mode of injury was fall in 28 cases, road traffic accident in 2 cases.

\begin{tabular}{|c|c|c|c|}
\hline & & Number & Percent \\
\hline Valid & C1 & 7 & 23.3 \\
\hline & C2 & 5 & 50 \\
\hline & C 3 & 8 & 26.7 \\
\hline & Total & $\mathbf{3 0}$ & $\mathbf{1 0 0}$ \\
\hline \multicolumn{4}{|c|}{ Type of Fracture } \\
\hline
\end{tabular}

7 fractures were classified as AO type C1, 15 fractures as AO type $\mathrm{C}$ and 8 fractures as $\mathrm{AO}$ type $\mathrm{C} 3$.

\begin{tabular}{|c|c|c|}
\hline & Frequency & Percent \\
\hline Valid same day & 15 & 50 \\
Within one week & 13 & 43.3 \\
>1 week & 2 & 6.7 \\
Total & $\mathbf{3 0}$ & $\mathbf{1 0 0}$ \\
\hline \multicolumn{2}{|c|}{ Time of Fixation } \\
\hline
\end{tabular}

Most of the cases operated on the same day or next day of attending the emergency dept.

Out of the 30 cases, 15 cases (50\%) were operated within a week of injury and 13 cases between 8 to 14 days. The delay if any was on the part of the patients presenting late.

\section{Post-Operative Infection}

No patients had post-operative wound infection

\section{Anatomical Evaluation \\ Residual Dorsal Tilt}

Dorsal tilt (from a neutral of zero degrees) of the distal radial articular surface varied from $5^{\circ}$ to $25^{\circ}$. Post-operatively, the dorsal tilt could be corrected to the anatomical palmar tilt or at least a neutral angle in 20 patients (66.7\%). While in 10 patients $(33.3 \%)$, the dorsal tilt could not be restored even to a neutral angle.

At the final follow-up, 22 patients (73.3\%) had excellent results. In 8 patients, $(6.4 \%)$ of the patients had good result.

\begin{tabular}{|c|c|c|}
\hline & Frequency & Percent \\
\hline Valid Excellent & 22 & 73.3 \\
Good & 6 & 20.0 \\
Fair & 1 & 3.3 \\
Poor & 1 & 3.3 \\
Total & $\mathbf{3 0}$ & $\mathbf{1 0 0}$ \\
\hline \multicolumn{2}{|c|}{} \\
\hline
\end{tabular}

\begin{tabular}{|c|c|c|}
\hline & $\begin{array}{c}\text { RDT Excellent Good } \\
\text { Fair Poor }\end{array}$ & Total \\
\hline $\begin{array}{c}\text { (RDT) poor count } \\
\text { \% within RDT }\end{array}$ & 22611 & 30 \\
\hline Total count & 226.03 .33 .3 & $100.0 \%$ \\
\% within RDT & 73.320 .03 .33 .3 & 30 \\
\hline \multicolumn{2}{|c|}{ Cross Tab } \\
\hline
\end{tabular}

\begin{tabular}{|c|c|c|c|}
\hline & FU1 (RDT)- & FU2 (RDT)- & RDT-(RDT) \\
RDT & RDT & RD \\
\hline Z & -4.983 & -4.983 & -4.973 \\
$\begin{array}{c}\text { Asymp. Sig. (2 } \\
\text { tailed) }\end{array}$ & .000 & .000 & .000 \\
\hline \multicolumn{3}{|c|}{ Test Statistics* } \\
\hline
\end{tabular}

*Wilcoxon Signed Rank Test

Radial Shortening

\begin{tabular}{|c|c|c|}
\hline & Frequency & Percent \\
\hline Valid Excellent & 23 & 76.7 \\
Good & 6 & 20.0 \\
Poor & 1 & 3.3 \\
Total & $\mathbf{3 0}$ & $\mathbf{1 0 0}$ \\
\hline \multicolumn{2}{|c|}{} \\
\hline
\end{tabular}




\begin{tabular}{|c|c|c|}
\hline & RS Excellent Good Poor & Total \\
\hline Fair count & 310 & 4 \\
\% within (RS) & 7525 & $100.0 \%$ \\
(RS) poor count & 2051 & 26 \\
\% within (RS) & 76.919 .23 .8 & 100 \\
\hline Total count & 2361 & 30 \\
\% within (RS) & 76.720 .03 .3 & $100.0 \%$ \\
\hline \multicolumn{2}{|c|}{ Cross Tab } \\
\hline
\end{tabular}

\begin{tabular}{|c|c|c|c|}
\hline & FU1 (RS)- RS & FU2(RS)- RS & RS-(RS) \\
\hline Z & -4.928 & -4.928 & -4.910 \\
$\begin{array}{c}\text { Asymp. Sig. } \\
\text { (2 tailed) }\end{array}$ & .000 & .000 & .000 \\
\hline \multicolumn{4}{|c|}{ Test Statistics* } \\
\hline
\end{tabular}

\section{*Wilcoxon Signed Rank Test}

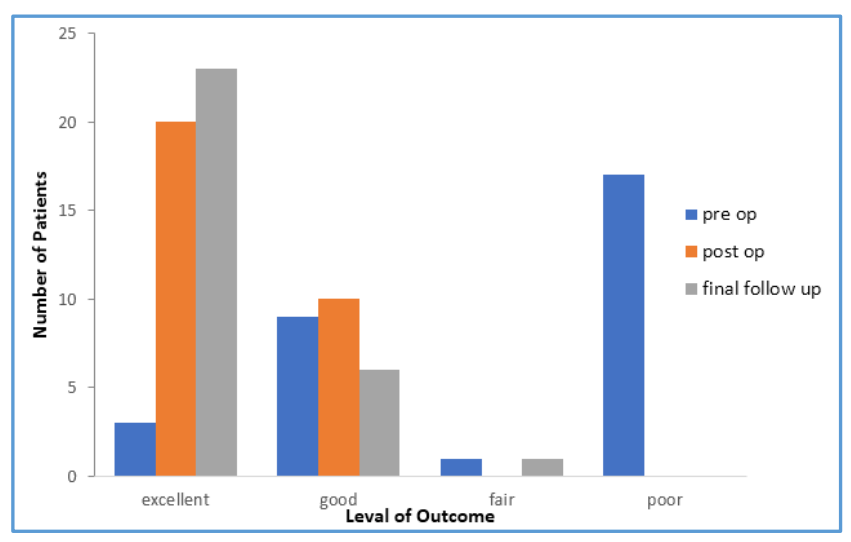

Of 30 patients, 23 patients had excellent $<3 \mathrm{~mm}$ outcome.

\section{Radial Angle}

\begin{tabular}{|c|c|c|}
\hline & FU2-DEF Excellent Good & Total \\
\hline (LORI) Good count & 1 & 1 \\
\% within (LORI) & 100 & $100.0 \%$ \\
Fair count & 11 & 2 \\
\% within (LORI) & 5050 & 100 \\
Poor count & 198 & 27 \\
\% within (LORI) & 70.429 .6 & 100 \\
\hline Total count & 2010 & 30 \\
\% within (RS) & 66.733 .3 & $100.0 \%$ \\
\hline \multicolumn{2}{|c|}{ Cross Tab } \\
\hline
\end{tabular}

\begin{tabular}{|c|c|c|}
\hline & $\begin{array}{c}\text { LORI } \\
\text { Excellent Good Fair Poor }\end{array}$ & Total \\
\hline (LORI) good count & 1 & \\
\% within & 100 & \\
Fair count & 2 & $100.0 \%$ \\
\% within & 100 & \\
Poor count & 24111 & 30 \\
\% within & 88.93 .73 .73 .7 & $100.0 \%$ \\
\hline Total count & 26211 \\
\%within RDT & 86.76 .73 .33 .3 & \\
\hline \multicolumn{2}{|c|}{ Cross Tab } \\
\hline
\end{tabular}

\begin{tabular}{|c|c|c|c|}
\hline & $\begin{array}{c}\text { FU1 (LORI) } \\
\text { FU2 -DEF- } \\
\text { (LORI) }\end{array}$ & $\begin{array}{c}\text { FU3(LORI) FU3- } \\
\text { DEF- (LORI) RS }\end{array}$ & $\begin{array}{c}\text { LORI- } \\
\text { (LORI) }\end{array}$ \\
\hline $\begin{array}{c}\text { Z } \\
\text { Asymp. Sig. } \\
\text { (2 tailed) }\end{array}$ & $\begin{array}{c}-4.886 \\
.000\end{array}$ & $\begin{array}{c}-4.886 \\
.000\end{array}$ & $\begin{array}{c}-5.012 \\
.000\end{array}$ \\
\hline \multicolumn{3}{|c|}{ Test Statistics* } \\
\hline
\end{tabular}

\footnotetext{
*Wilcoxon Signed Rank Test
}

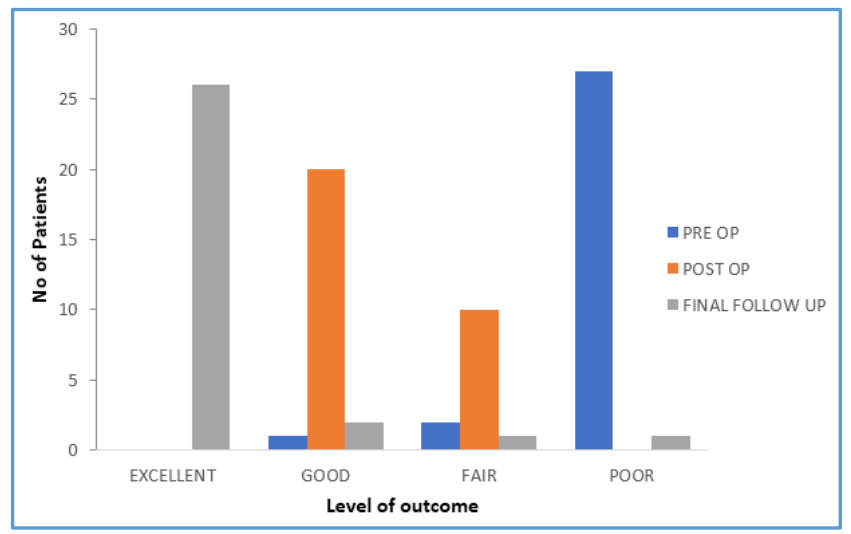

\section{Clinical and Functional Evaluation}

\section{Subjective Evaluation}

Subjectively, out of 30 patients 22 patients (73.3\%) had excellent, 5 patients (14.6\%) had good and 2 patients had fair $(6.6 \%)$ and 1 patient had poor $(3.3 \%)$ results.

\begin{tabular}{|c|c|}
\hline Subjective Evaluation & Number of Patients \\
\hline Excellent & 22 \\
Good & 5 \\
Fair & 2 \\
Poor & 1 \\
Total & $\mathbf{3 0}$ \\
\hline
\end{tabular}

One poor result was due to the dislodgment of Kirschner wire following alcoholic withdrawal seizures.

\begin{tabular}{|c|c|c|}
\hline & $\begin{array}{c}\text { P and D } \\
\text { Excellent Good }\end{array}$ & Total \\
\hline (P and D) Excellent & 913 & 22 \\
count & 40.959 .1 & 100 \\
\% within & 5 & 5 \\
Good count & 100 & 100 \\
\% within & 2 & 2 \\
Fair count & 100 & 100 \\
\% within & 1 & 1 \\
Poor count & 100 & 100 \\
\% within & 921 & 30 \\
\hline Total count & 3070 & $100.0 \%$ \\
\% within & Cross Tab \\
\hline \multicolumn{2}{|c}{} \\
\hline
\end{tabular}

\begin{tabular}{|c|c|c|c|}
\hline & $\begin{array}{c}\text { FU (P and DI) } \\
\text { (P and D) }\end{array}$ & $\begin{array}{c}\text { P and D-(P } \\
\text { and D) }\end{array}$ & $\begin{array}{c}\text { P and D-(P } \\
\text { and D) }\end{array}$ \\
\hline $\begin{array}{c}\text { Asymp. Sig. (2 } \\
\text { tailed) }\end{array}$ & -.849 & -2.858 & -2.065 \\
& .396 & .004 & .039 \\
\hline \multicolumn{4}{|c|}{ Test Statistics* } \\
\hline
\end{tabular}

*Wilcoxon Signed Rank Test

\begin{tabular}{|c|c|c|}
\hline & $\begin{array}{c}\text { DF } \\
\text { NIL Yes }\end{array}$ & Total \\
\hline (DF) yes count & 291 & 30 \\
\% within (DF) & 96.73 .3 & $100 \%$ \\
\hline Total count & 291 & 30 \\
\% within (RS) & 96.73 .3 & $100.0 \%$ \\
\hline \multicolumn{3}{|c|}{ Cross Tab } \\
\hline
\end{tabular}




\begin{tabular}{|c|c|c|c|}
\hline & DF-(DF) & DF-(DF) & DF-(DF) \\
\hline Z & -5.196 & -4.000 & -5.385 \\
$\begin{array}{c}\text { Asymp. Sig. (2 } \\
\text { tailed) }\end{array}$ & .000 & .000 & .000 \\
\hline \multicolumn{3}{|c|}{ Test Statistics* } \\
\hline
\end{tabular}

*Wilcoxon Signed Rank Test

\begin{tabular}{|c|c|c|}
\hline & PF NIL Yes & Total \\
\hline (PF) Yes count & 282 & 30 \\
\% within (PF) & 93.36 .7 & $100 \%$ \\
\hline Total count & 2982 & 30 \\
\% within (PF) & 93.36 .7 & $100.0 \%$ \\
\hline \multicolumn{2}{|c|}{ Cross Tab } \\
\hline
\end{tabular}

\begin{tabular}{|c|c|c|c|}
\hline & PF-(PF) & PF-(PF) & PF-(PF) \\
\hline Z & -5.292 & -5.292 & -5.292 \\
$\begin{array}{c}\text { Asymp. Sig. (2 } \\
\text { tailed) }\end{array}$ & .000 & .000 & .000 \\
\hline \multicolumn{3}{|c|}{ Test Statistics* } \\
\hline
\end{tabular}

*Wilcoxon Signed Rank Test

\begin{tabular}{|c|c|c|}
\hline & RD NIL Yes & Total \\
\hline (RD) Yes count & 291 & 30 \\
\% within (RD) & 96.73 .3 & $100 \%$ \\
\hline Total count & 291 & 30 \\
\% within (RD) & 96.73 .3 & $100.0 \%$ \\
\hline \multicolumn{2}{|c|}{ Cross Tab } \\
\hline
\end{tabular}

\begin{tabular}{|c|c|c|c|}
\hline & RD-(RD) & RD-(RD) & RD-(RD) \\
\hline Z & -5.385 & -5.385 & -5.385 \\
$\begin{array}{c}\text { Asymp. Sig. (2 } \\
\text { tailed) }\end{array}$ & .000 & .000 & .000 \\
\hline \multicolumn{3}{|c|}{ Test Statistics* } \\
\hline
\end{tabular}

*Wilcoxon Signed Rank Test

\begin{tabular}{|c|c|c|}
\hline & UD NIL Yes & Total \\
\hline (UD) Yes count & 291 & 30 \\
\% within (UD) & 96.73 .3 & $100 \%$ \\
\hline Total count & 291 & 30 \\
\% within (UD) & 96.73 .3 & $100.0 \%$ \\
\hline \multicolumn{2}{|c|}{ Cross Tab } \\
\hline
\end{tabular}

\begin{tabular}{|c|c|c|c|}
\hline & UD-(UD) & UD-(UD) & UD-(UD) \\
\hline Z & -5.385 & -5.385 & -5.385 \\
$\begin{array}{c}\text { Asymp. Sig. (2 } \\
\text { tailed) }\end{array}$ & .000 & .000 & .000 \\
\hline \multicolumn{3}{|c|}{ Test Statistics* } \\
\hline
\end{tabular}

*Wilcoxon Signed Rank Test

\begin{tabular}{|c|c|c|}
\hline & PR NIL Yes & Total \\
\hline (PR) Yes count & 291 & 30 \\
\% within (PR) & 96.73 .3 & $100 \%$ \\
\hline Total count & 291 & 30 \\
\% within (PR) & 96.73 .3 & $100.0 \%$ \\
\hline \multicolumn{2}{|c|}{ Cross Tab } \\
\hline
\end{tabular}

\begin{tabular}{|c|c|c|c|}
\hline & PR-(PR) & PR-(PR) & PR-(PR) \\
\hline Z & -5.385 & -5.385 & -5.385 \\
$\begin{array}{c}\text { Asymp. Sig. (2 } \\
\text { tailed) }\end{array}$ & .000 & .000 & .000 \\
\hline \multicolumn{3}{|c|}{ Test Statistics* } \\
\hline
\end{tabular}

*Wilcoxon Signed Rank Test

\begin{tabular}{|c|c|c|}
\hline & SU NIL Yes & Total \\
\hline (SU) Yes count & 291 & 30 \\
\% within (SU) & 96.73 .3 & $100 \%$ \\
\hline Total count & 291 & 30 \\
\% within (SU) & 96.73 .3 & $100.0 \%$ \\
\hline \multicolumn{2}{|c|}{ Cross Tab } \\
\hline
\end{tabular}

\begin{tabular}{|c|c|c|c|}
\hline & SU-(SU) & SU-(SU) & SU-(SU) \\
\hline Z & -5.385 & -5.385 & -5.385 \\
$\begin{array}{c}\text { Asymp. Sig. (2 } \\
\text { tailed) }\end{array}$ & .000 & .000 & .000 \\
\hline \multicolumn{4}{|c|}{ Test Statistics* } \\
\hline
\end{tabular}

*Wilcoxon Signed Rank Test

\section{Objective Evaluation}

\begin{tabular}{|c|l|}
\hline Loss of dorsiflexion $(<45$ degrees $)$ & 1 \\
\hline Loss of palmar flexion $(<30$ degrees $)$ & 2 \\
\hline Loss of ulnar deviation $(<15$ degrees $)$ & 1 \\
\hline Loss of radial deviation $(<15$ degrees $)$ & 1 \\
\hline Loss of supination $(<50$ degrees $)$ & 1 \\
\hline
\end{tabular}

\section{RESULTS}

\section{Anatomical Score of Healed Fracture}

The scoring was done according to the Sarmiento's modification of Lindstrom's criteria.

Anatomically, 23 patients (76.6\%) had excellent restoration of anatomy. 5 patients (16.6\%) had good restoration and 1 had fair $(3.3 \%)$ and 1 had poor (3.3\%) restoration of anatomy. Thus, $93.3 \%$ patients had excellent-to-good alignment of fragments and good reduction could not be achieved in $6.7 \%$ patients resulting in fair or poor results.

\section{Functional End Results of Healed Fracture}

The scoring of healed fracture was done according to the demerit point system of Gartland and Werley with Sarmiento et al's modification. Functionally, 26 patients $(86.6 \%)$ had excellent, 2 good (6.6\%), 1 patient had fair $(3.3 \%)$ and 1 had poor $(3.3 \%)$ restoration of functions. Poor function correlated with residual displacement and poor patient compliance.

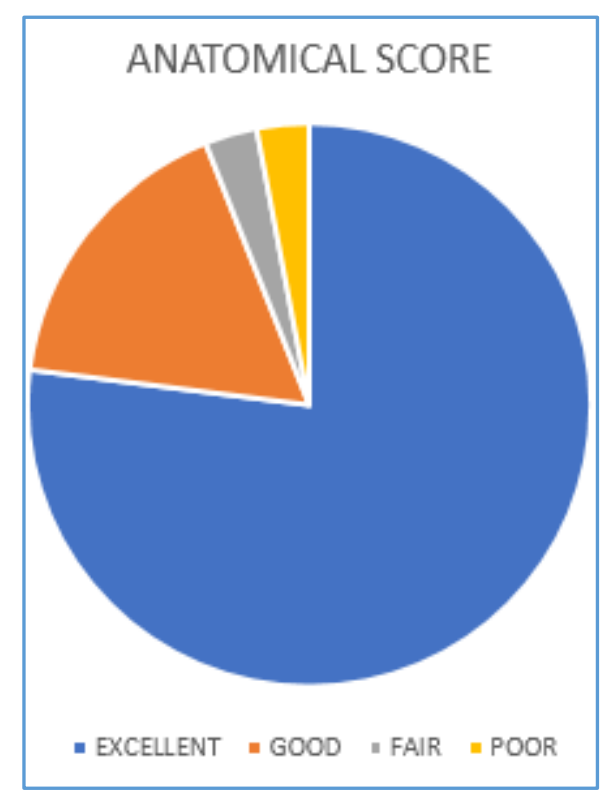




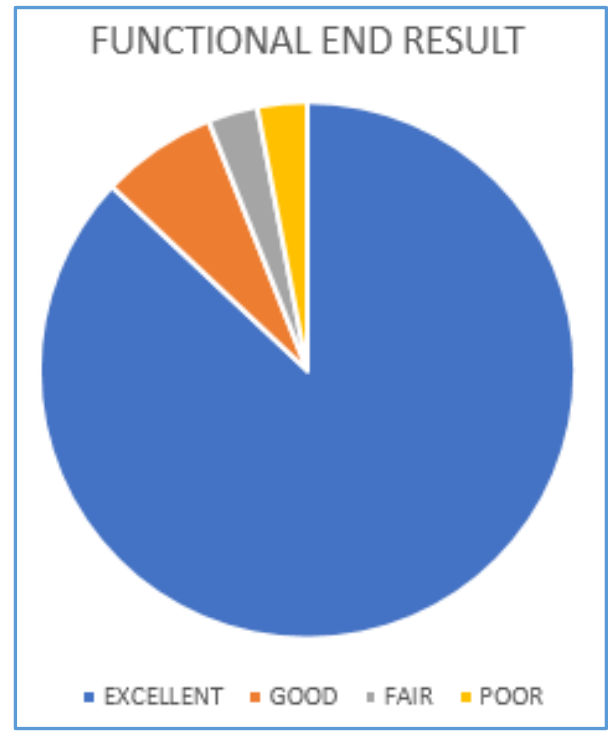

\section{DISCUSSION}

There are various treatments for comminuted distal radius fractures.(10) One of them is open reduction and internal fixation with buttress plating.(7) Surgical treatment plating ensures more consistent correction of displacement and maintenance of reduction of fragments.(11,2) The technique of fixation depends on fracture displacement, joint involvement, patient's age, bone quality, surgeon's experience, etc.

In 1908, Lambotte suggested single pin placement through radial styloid as a mean of stabilising the distal radius fracture.(1) Raymond et al suggested placement of volar plate is important in the fixation of fragments.(12) Rate of complication in volar fixation varies between $8 \%$ and $30 \%$ including infection, wire breakage, prominent implant, tendon rupture, etc.(13,2) Combined volar and dorsal plate fixation has been suggested by many including Can U et al (2008), but with high rate of complication like complex regional pain syndrome.

In the final evaluation of our study, out of 30 patients 23 had excellent results and 5 had good results and one had fair result. Final one result was due to displacement of K-wire from the withdrawal seizure. We had more excellent functional results (86\%) than anatomical results $(76.6 \%)$. And the poor results were due to poor patient compliance. Our results suggest that the radial styloid collapse and malunion of distal radius can be prevented by anti-impaction $\mathrm{K}$-wire through radial styloid. The disadvantage of our study is that for intraarticular fracture late changes like arthritis is not included.

\section{CONCLUSION}

From this study, we have obtained 93\% anatomical and 93\% functional, excellent-to-good results. Our observations suggest that stabilising distal radial fractures using volar plate fixation and anti-impaction $\mathrm{K}$-wire fixation through radial styloid is an effective method to prevent distal metaphyseal collapse and maintaining the reduction till union, even when the fracture is grossly comminuted/ intra-articular and unstable.
The advantage of our study is that it is a simple method, which is cost effective. Disadvantages include patient has to be immobilised with short-arm slab for a period of four weeks. Since we are keeping the tip of K-wires outside, there are chances of infection and dislodgement of $\mathrm{K}$-wire since the follow-up period is one year and later complications such as arthritis are not studied. This is the limitation of this study.

The technique emphasises that open reduction and internal fixation with volar plating and anti-impaction K-wire through radial styloid has excellent functional outcome with minimal complications. Thus, proving that it is an effective modality of treatment for AO types C1, C2 and C3 fractures of distal radius in patient's age group between 30 and 50 with good bone stock as well as early osteoporotic patients.

\section{ACKNOWLEDGEMENT}

Sincere thanks to Mrs. Girija, our confidential assistant and Dept. of Orthopaedics, Govt. Medical College, Calicut. Sincere thanks to members of Institutional Research Committee.

\section{REFERENCES}

[1] Bucholz RW, Heckman JD. Rockwood \& Green's fractures in adults. $5^{\text {th }}$ edn. Philadelphia: Lippincott Williams \& Wilkins 2001: p. 815-67.

[2] Weber ER. Rational approach for recognition and treatment of collis fracture. Hand Clin 1987;3(1):13-21.

[3] Musgrave DS, Idler RS. Volar fixation of dorsally displaced distal radius fractures, using the 2.4-mm locking compression plate. J Hand Surg 2005;30(4):743-9.

[4] Owen RA, Melton LJ, Johnson KA, et al. Incidence of Colles' fracture in a North American community. Am J Public Health 1982;72(6):605-7.

[5] Colles A. On the fracture of the carpal extremity of the radius. Edinburgh Med Surg 1814;10:182-6.

[6] Colles A. The classic. On the fracture of the carpal extremity of the radius. Abraham Colles, Edinburgh Med Surg J 1814. Clin Orthop Relat Res 1972;83:3-5.

[7] Leung KS, Shen WY, Tsang HK, et al. An effective treatment of comminuted fractures of distal radius. J Hand Surg Am 1990;15(1):11-7.

[8] Szabo RM. Extra articular fractures of distal radius. Orthop Clin North Am 1993;24(2):229-37.

[9] Belloti JC, Tamaoki MJ, Atallah AN, et al. Treatment of reducible unstable fractures of distal radius in adults: a randomised controlled trial of De-Palma percutaneous pinning $\mathrm{v} / \mathrm{s}$ bridging external fixation. BMC Musculoskeletal Disorder 2010;11:137.

[10] Cooney WP. Fractures of distal radius. A modern treatment-based classification. Orthop Clin Relat Res 1993;24(2):211-6.

[11] Ellis J. Smith's and Barton's fractures. A method of treatment. JBJS Br 1965;47(4):724-7.

[12] Thomas FB. Reduction of Smith's fracture. JBJS Br 1957;39-B(3):463-70.

[13] Chung KC, Watt AJ, Kotsis SV, et al. Treatment of unstable distal radial fractures with volar locking plating system. JBJS 2006;88-A(12):2687-94. 